\title{
Applying Customer Journey Map for Categorizing ERP Functions to Improve Customer Satisfaction
}

\author{
Hitoshi NAKAO ${ }^{1}$, Yoshikatsu FUJITA ${ }^{2}$ and Kazuhiko TSUDA ${ }^{3+}$ \\ ${ }^{1}$ Department of Risk Engineering, University of Tsukuba, Tokyo, Japan \\ ${ }^{2}$ Department of Sociology, Teikyo University, Tokyo, Japan \\ ${ }^{3}$ Graduate School of Business Sciences, University of Tsukuba, Tokyo, Japan
}

\begin{abstract}
When introducing ERP systems which would fit the existing business module, it is important to analyze the correspondence relation between ERP functions and business operations. This study proposes to compare the function of ERP with the business module and verifies the effectiveness of the ERP in the point of customer satisfaction. Managers and accounting personnel used to share different opinions for using ERP and to find different satisfaction from ERP. This study verifies the customer satisfaction depending on their responsibilities. For analyzing customer satisfaction, this paper applies the customer journey map method, which is usually employed in service industries. By categorizing satisfaction and importance in two axes, this paper clarifies items of low satisfaction and those of high importance. Finally, this report analyzes the cause of dissatisfaction, shows deficiencies ERP potentially holds, and presents which function should be customized.
\end{abstract}

Keywords: ERP, customer journey map

\section{Introduction}

With the development of computer environment, many company deals with accounting treatment by the system. By the birth of packaged software Enterprise Resource Planning of (ERP), the systems of various departments are integrated and rationalized. As a result, the environments of the information are improved. For example the manager can confirm the data of all sectors of the company in timely. However, even if the company implement ERP system, their work does not become efficient. Major reasons are the differences of the business content and origin of the company. This study shows how to analyze the customer satisfaction in the ERP around the accounting part of the ERP, and this study reveal the cause of dissatisfaction.

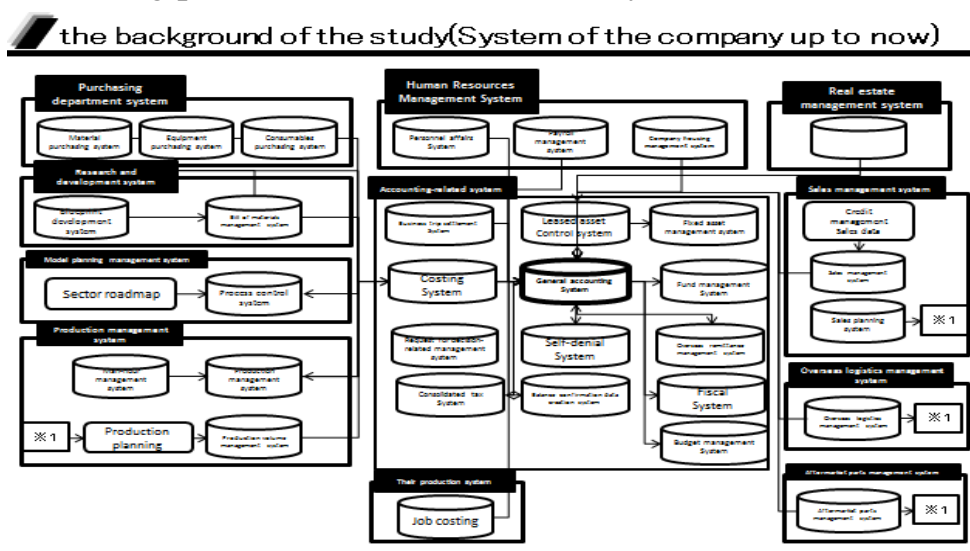

Fig. 1: Examples of business system.

\footnotetext{
+ Corresponding author.

E-mail address: s1430169 @gssm.otsuka.tsukuba.ac.jp
} 
As shown in this example, in some companies the programmer construct each department a variety of systems in accordance with many requirements of the user sectors. In this case, the mechanism that meets the requirements of each is created. However, the specifications of the master file to be used across multiple departments are different by the each systems. So, coordination between systems is difficult in some cases. Even if the systems can be linkage, the problem that is difficult to browse the data in real time occurs. The another problem that is difficult to multilingual if the system is constructed for each sector occurs. In the early 1990s, ERP was developed in the United States and it became popular. ERP is a system that embodies the management techniques of successful companies in the world. Also it can support multi-lingual and manage the data centrally, it can be updated and viewable in real time. With the introduction of ERP, various problems have been resolved. The Figure 2 shows the example.

Broken line portion of Figure 2 is the function that the ERP has. Implementation of ERP can become not only simplify whole the function but also centralization the data and possibility of collaboration between departments. As shown in Figure 2, ERP has a variety of functions. ERP are trying to provide the functions that accounting personnel use by their basic functions, their case template functions and customization. If the functions of their basic functions and case template functions are insufficient, the company must be introduce the ERP by the customization over the enormous cost. But they often have the problem that the effect of assuming is very few in spite of the huge cost for the customization. As a result, accounting personnel are doing a lot of work manual, spreadsheet software and so on, in order to compensate for insufficient functions.

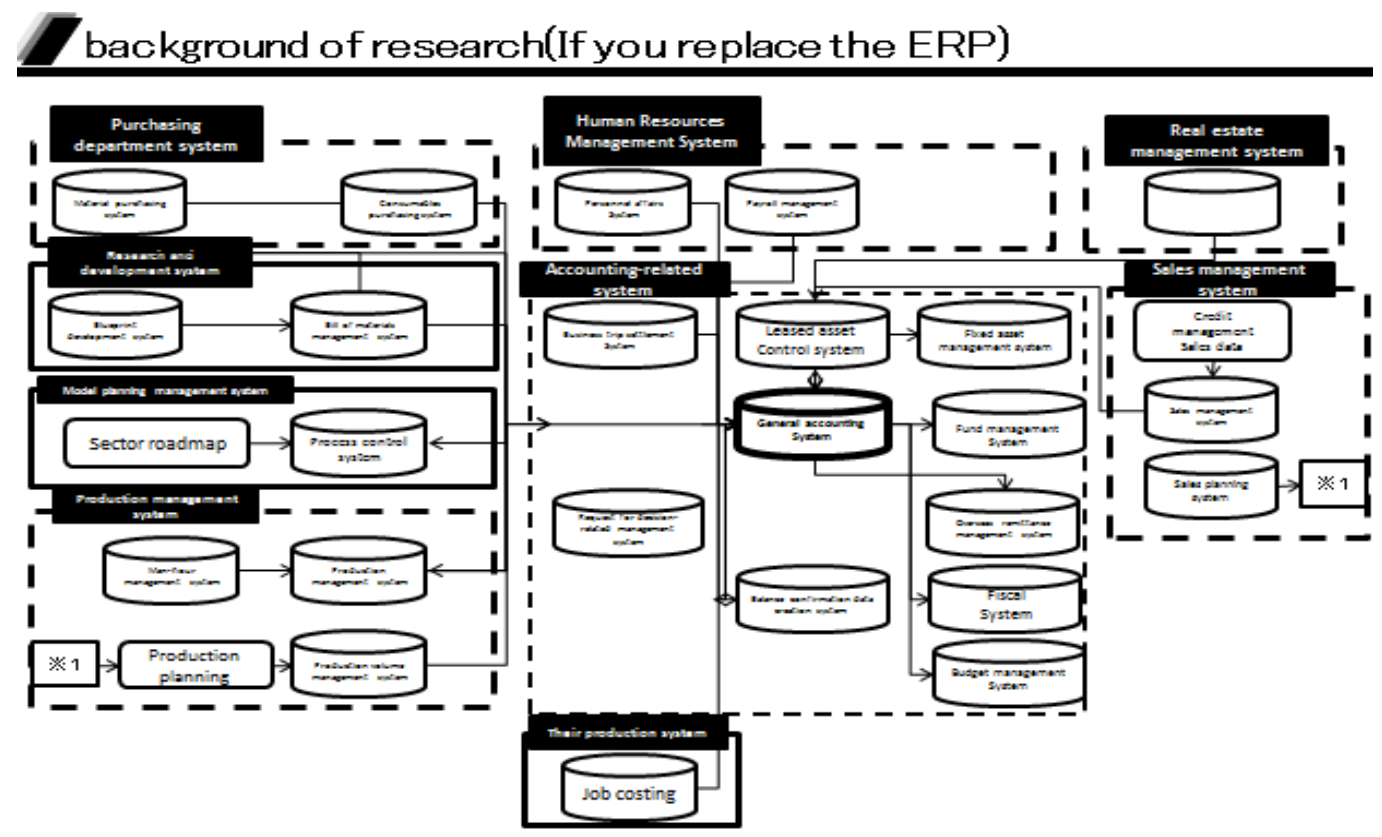

Note: The flow diagram are fictitious and are not intended any real company actually.

Fig. 2: After introducing ERP.

\section{Previous Work}

Yabuhara, Ogata [1] et al analyze the cooperation of accounting and management accounting, and the structure of the accounting by comparing Oracle with SAP which are the typical example of the ERP system. It is interesting to compare the management accounting and accounting by replacing the function of the ERP system. However, they have not compare the functionality or usability of ERP from the business the actual situation of accounting personnel, and not compare the product in terms of customer satisfaction with the ERP from the accounting personnel.

Colette Rolland [2], says it is more efficient gradually introduction of the function during the ERP implementation for the reflection of the full functional requirements about the customer requirements. However, she do not analyze in terms of the user who actually used, is in terms of satisfaction of accounting personnel. 
Petra Schubert and Philip Holst Riis [3] describe the contents of the terms and revision or when versionup of the ERP software. They says how to build the ecosystem among the company that created the ERP, the company that sells it to build a software value-added to the ERP and company that actually introduced the ERP customer and about how conduct small revision of the bug up and upgraded on a regular basis. However, they do not refer to the satisfaction of the accounting personnel at the time of performing the upgrade or update.

\section{The Verification Method in this Study}

\subsection{Definition of Customer Journey Map}

Customer Journey map is defined as follows[4]. (1)A modeling tool for visual representation of emotional state of the customer when they received interaction that required the customer needs. (2)A modeling tool for visual representation of emotional state of the customer needs at different stages of the process when a customer uses the service. Elements of the customer journey map is not normalized.

\subsection{Application of customer journey map}

Even if ERP works effectively in one company, it does not always work in another company due to the low satisfaction of the manager or accounting personnel. In this study, the degree of ERP support for critical business is analyzed.

The customer satisfaction with ERP and the importance of business are evaluated by applying the customer journey map. The importance of business is evaluated by five levels along the flow on the actual business of the customer. Evaluation of 5 means that one particular important business, without which it is impossible to conduct business. Evaluation of 3 means it takes a great deal of effort, without which it is possible to conduct business.

Also about each business, ERP is evaluated in five levels of whether it is possible to conduct business enough for the person in charge. As a result that satisfaction is gotten. The 5th degree of satisfaction means that they can conduct the business of the current situation without change the standard function of ERP. The 1 st degree of satisfaction means that they can't conduct the business of the current situation without change the standard function of ERP. The 3rd degree of satisfaction means that they can conduct the business of the current situation on big effort without change the standard function of ERP.

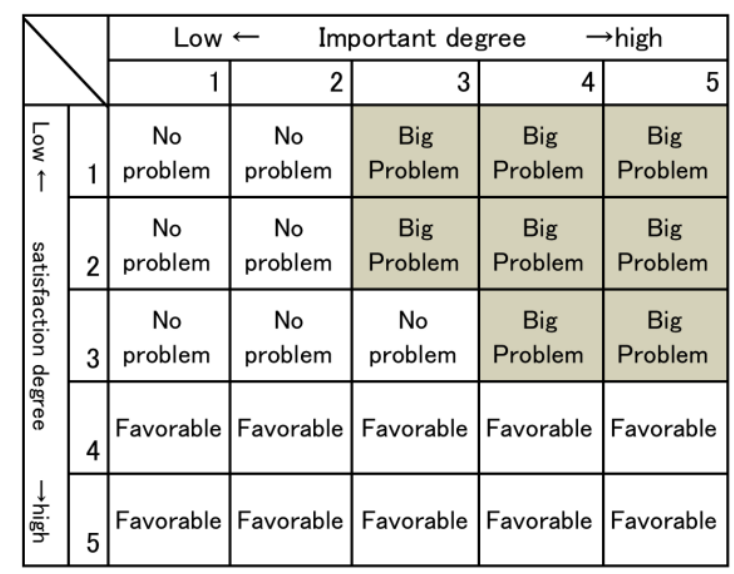

Fig. 3: Importance and Satisfaction for ERP functionality.

The customer think that there is no big problem with the function of ERP, because of the business's importance is low level if the degree of satisfaction about standard ERP function is low level. The customer think that the function of ERP is good if the standard ERP function fit the business. The customer consider that there is no big problem with the function of ERP. Because of the business's importance is low level in spite of low level about the degree of satisfaction about standard ERP function. The customer think that there is big problem with the function of ERP, because of the business's importance is high level if the degree of satisfaction about standard ERP function is low level. 


\subsection{The method of this study}

The subject to be analyzed in this study are the management and the accounting personnel who take advantage of ERP. The interviews were performed to clarify the satisfaction and importance of the work. The interviews were conducted to the section manager as the management. The interviews were conducted to the person in charge of three people doing accounting work in practice as the accounting personnel. ERP that is evaluated is Oracle EBS. "General Accounting Guide for E-business" [5] that is used to consider the introduction is used this study. The problem of ERP is analyzed by using class diagram and activity diagram of the Oracle EBS and one company.

\section{Result}

Customer Journey Map describes the flow of the actual business in the horizontal axis. And it describes in the vertical axis, the business flow at the top and the person involved in business and the function of providing ERP in the lower portion. Each cell is associated with the business by line.

It was decided the level of satisfaction and the reason of the management and accounting personnel who use the ERP through the interview. It showed the average the level of satisfaction of three. Also, the level of importance has similar structure of the level of satisfaction. Figure 4 show customer journey map of the business of the purchase management system (AP).
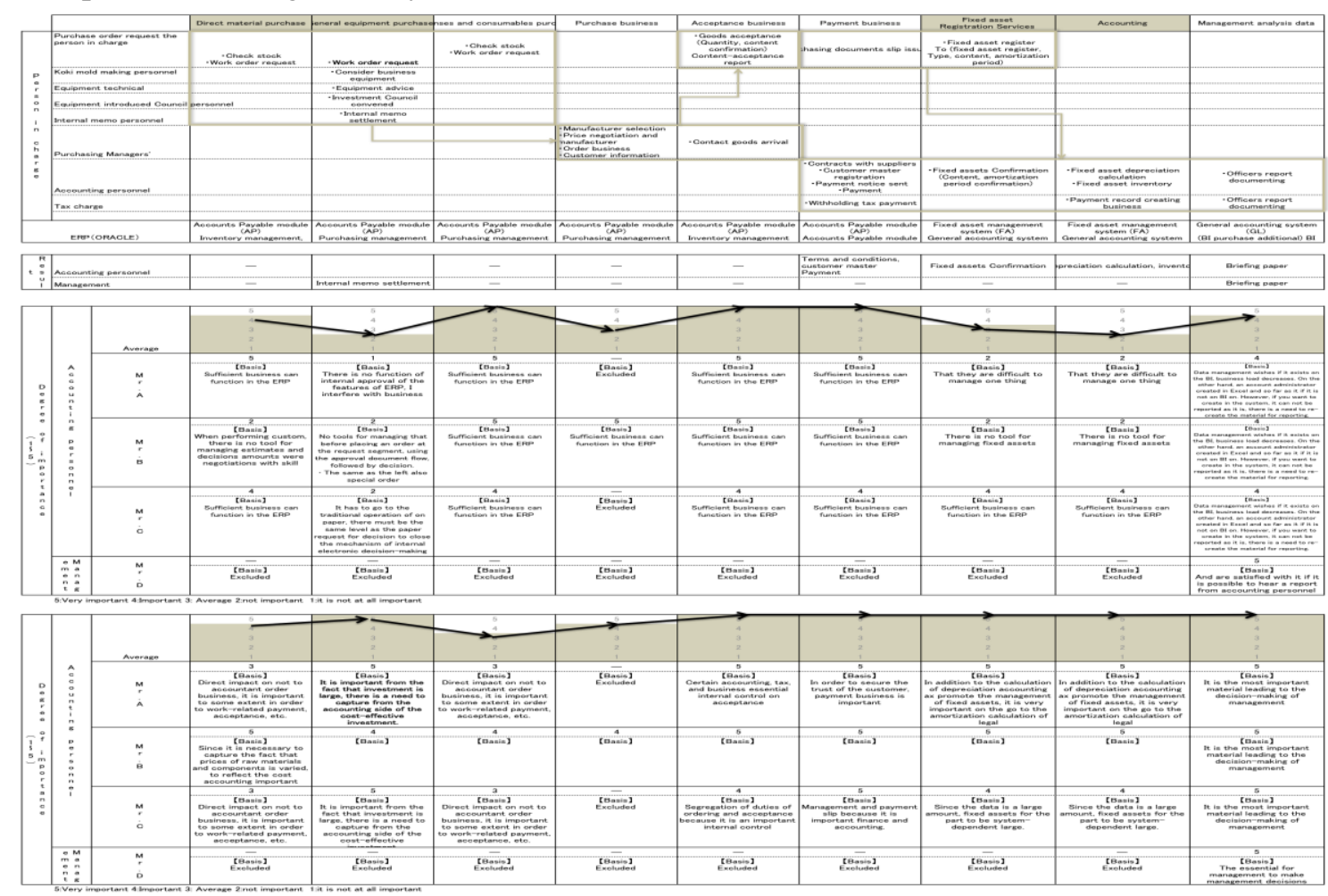

Fig. 4: Customer journey map of AP points

As a result of the interview manager is not interested in the function of ERP. Their interest is the report that accounting personnel create as management accounting with the help of ERP. Perhaps their interests are numerical value of report which accounting personnel has created. Their interest is not numerical value which ERP provide.

On the other hand it become clearly that, although the functions of the below are important, the accounting personnel are not satisfied with them. They are the procedure for purchasing fixed assets and for management of fixed assets after purchase at the functions of the AP. The support functions of ERP and accounting operations are compared on the business purchase of fixed assets.

Purchase flow of fixed assets that ERP provide is the same as the normal purchase flow of material and consumables. 
It is flow that the department who wish to purchase put an order request to the purchasing department , the purchasing department accept the goods and the purchase is complete ( Fig.5 ).

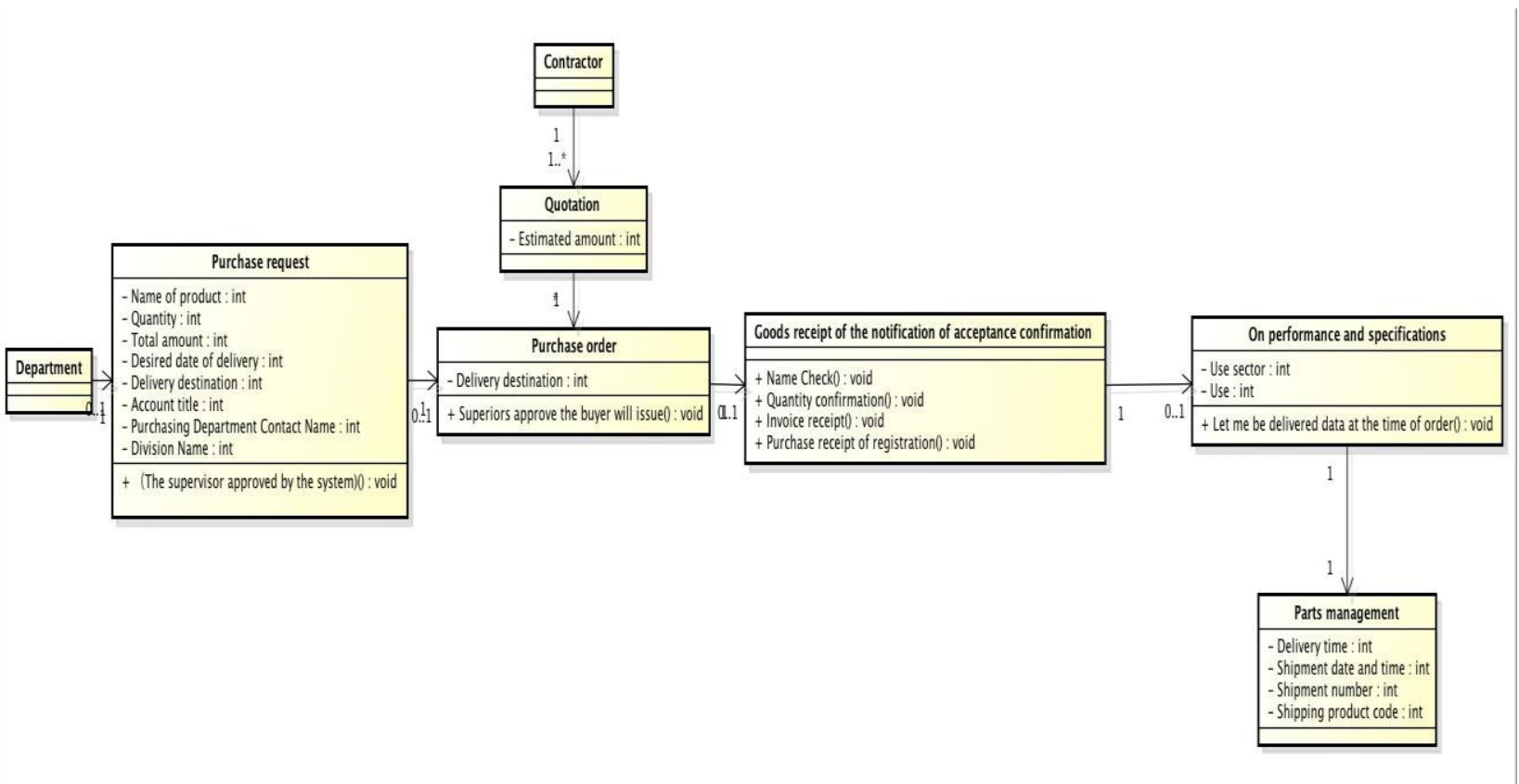

Fig. 5: Operations of ERP of Fixed assets purchasing

The fixed assets purchasing operations of the companies do below material operation. (1)Department which want to purchase consider buying , (2)Holding investment council during the period order , (3)Request for decision , (4)management of frame of investment.

At the investment council, the fixed assets purchasing which will be bought by turning on big money is verified profitability and validity of the purchase by the professional group of equipment.

At the request for decision, the person in charge of the department describe to the approver of the request for decision about validity of the purchase and get the approval. The manager controls the spending, verifies the introduction rate of progress of the fixed assets and monitors on the changes in circumstances. ( Fig.6)

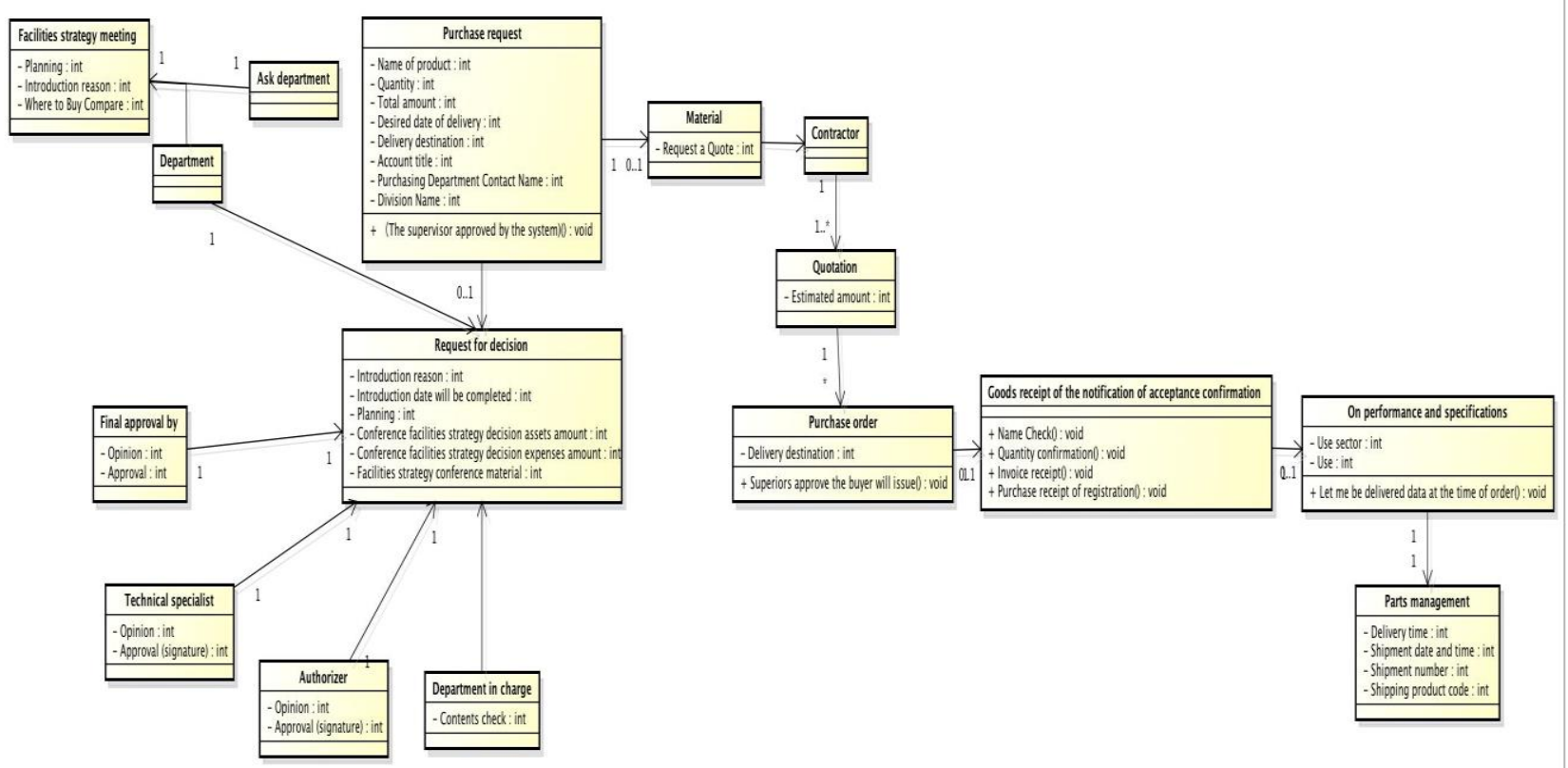

Fig. 6: Conceptual Model of Fixed assets purchasing 
The conceptual model of industries related to fixed assets purchasing is shown in Figure 6. As a result it become reveal that ERP does not have important function such as the investment council, the request for decision and the management of frame of investment.

This problem cannot be solved unless it is further examined doing the customization, taking advantage of the template that other companies created, doing hand management by accounting personnel to use another software Excel etc. or replacing the management method to another one.

\section{Conclusion}

This report clarifies problems which ERP systems potentially hold, from managers' and accounting personnel points of view. In order to analyze customer satisfaction, this paper applies the customer journey map, to carry out interviews about importance and the satisfaction for the ERP usability.

By categorizing satisfaction and importance in two axes, this paper clarifies items of low satisfaction and those of high importance. Finally, this report analyzes the cause of dissatisfaction, shows deficiencies ERP potentially holds, and presents some functions that should be customized. There are further tasks for future study upon these results such as,

( i ) Needs of customization and the volume of customization

(ii) Needs of the business improvement adapting for ERP functions

(iii) Selection criteria for choosing ERP

\section{Reference}

[1] Yabuhara, Ogata " Through comparison between Oracle EBS and architecture -SAP accounting system as seen from the information structure and the basic theory of accounting " UNISYS TECHNOLOGY REVIEW, vol101, P99-101, (2009)

[2] Colette Rolland "Matching ERP System Functionality to Customer Requirements ," Proceedings of the Fifth International Symposium on Requirements Engineering, (2001)

[3] .Philip Holst, Riis Petra Schubert " Upgrading to a New Version of an ERP System: A Multilevel Analysis of Influencing Factors in a Software Ecosystem " "2012 45th Hawaii International Conference on System Sciences "

[4] Masanao Takeyama "Service Design and Its Visualization Techniques" Keio University Hiyoshi Bulletin of Social Sciences (23), 15-35, 2012

[5] RIC Oracle Corporation Japan ,ASG Advisors Co., Ltd. "General Accounting Guide for E-Business " Ricktelecom (2001) 